\title{
Proposed System of New Generation LMS Using Visual Models to Accelerate Language Acquisition
}

\author{
Imad Hasan Tahini*, Alex Dadykin \\ Belarusian National Technical University (BNTU), Minsk, Belarus
}

\begin{tabular}{l} 
A R T I C L E I N F O \\
\hline Article history: \\
Received: 13 August, 2018 \\
Accepted: 02 October, 2018 \\
Online: 12 October, 2018 \\
\hline Keywords: \\
Learning Management System \\
(LMS) \\
Structural Visual Method (SVM) \\
Visual Auditory (VA) \\
Visual Model
\end{tabular}

\section{Introduction}

This paper is an extension of work originally presented in the Sixth International Conference on Digital Information, Networking, and Wireless Communications (DINWC), 2018, Beirut, Lebanon [1]. It presents the use of new methods to facilitate teaching and learning. The new results were obtained by using a Structural Visual Method and Visual Models and tools of systems analysis and information technologies. Distinguishing feature of this method is using colors to encode meanings in structural diagram.

The 21 st century is the century of the dominance of information and information technology. They are rapidly conquering the world, penetrating into all spheres of human activity, which led modern society to a general historical process called Informatics. This process consists in the free access of any citizen to information, penetration of information technologies into scientific, industrial, public spheres, high level of information services. To accelerate the acquisition of language for adults requires a new approach that differs about the traditional goal-

\footnotetext{
*Corresponding Author: Imad Hasan Tahini, Beirut, Lebanon,
} Email: imad.tahini@live.com setting, the selection of new education type, and is realized in a practical way.

Our research singled out among the teaching methods "central" - a support for the language and gives a practical experience of adult learners who, in the process of learning, analyze and understand, generalize and evaluate it. This is the basis for selecting the content of education, the choice of new methods and the organization of the pedagogical process as a whole.

Specificity of the organization of the pedagogical process by using new technology in the education of adults is due to the fact that, firstly, adults have educational needs, life experience and independence, which have grown from their practical activities and are vital for them; secondly, physiological and psychological features that affect the process of perception, assimilation and assessment of knowledge and skills, processing and adaptation of information; Thirdly, adults are directed to the rapid realization of acquired knowledge, skills and qualities; fourthly, all the educational activity of adults is determined by temporary, spatial, professional, domestic, social conditions. At the same time, it is necessary to take into account the contradictions inherent in the life and work experience of adult learners, the "plus" is that experience serves as a basis for a profound understanding of the problems 
under study, but "minus" in the existing stereotypes of thinking, established ideas that impede the perception of the new not appropriate. The effectiveness of the adult education process will be high when a person is put in the position of a researcher who independently searches for a solution and is able to coordinate it with others.

The goal of this article is to use the visual modeling system that helps you to learn how to build English sentences without thinking about rules and theoretical aspects. This work is under way to introduce this approach into training applications, programs and new type of LMS.

The visual model comes here to the rescue, allowing you to analyze English grammar not in words, but with the help of models, visual images. This model is abstract forms, colors, arrows, images. They are similar to the subway scheme. All schemes allow you to control meanings using a visual system that is much more powerful than a verbal one.

This method helps to understand the grammatical of English. In just one session you get a holistic view of the dynamics of English grammar. And this is important for an adult. Of course, this does not exclude the need for intensive training. But now it becomes clear what to train. In addition, today this article has a unique grammar training system, similar to which not met anywhere.

This paper is organized as follows, Section 2 we do the analysis of the research methods about possible training to get a new proposed way of competency. Section 3 we display the methods for improving adult's foreign language skills as well as the methodology of the study. Sections 4 we create the structure of new LMS. Section 5 we describe a stage of designing and development a new system for adults. The conclusion is discussed in the last section.

\section{Research of possible training ways}

Analysis of the model of the psyche [2], in spite of its simplicity, allows us to see interesting patterns.

The first conclusion is that the only thing that a person is able to manage and what it is possible to teach is activities and ways of doing it. As Galperin [3] showed, the training of mental activity necessarily includes the stage of its implementation in the form of external, physically performed actions.

Therefore, the acquisition and assimilation of information is only an intermediate stage in the process of forming the skills of performing certain activities and should not be an end in itself of the learning process, as often happens.

The second conclusion - motivation and interest are the most important component of the learning process, and without them the process cannot be effective.

The following is that human behavior is controlled only by a small degree of consciousness and thinking, and there are at least several different behavioral control loops, often unconscious and inaccessible to direct impact and change. The human psyche is a very complex and complex phenomenon, and any of its models, including the most detailed and complex, cannot reflect all its properties and ensure full compliance. Therefore, several simple models can bring more practical benefits than attempts to create a complete and all-encompassing model.

Let's consider known models of obtaining skills (competence) and trace the ways of their obtaining on the model of the psyche.

The model (Figure 1) for obtaining unconscious competence (skill), (usually attributed to Abraham Maslow [4], which is not true). It is widely known in the online learning environment and motivational and psychological training. It is structurally identical with the model of the psyche and is directly derived from it, and vice versa [2].

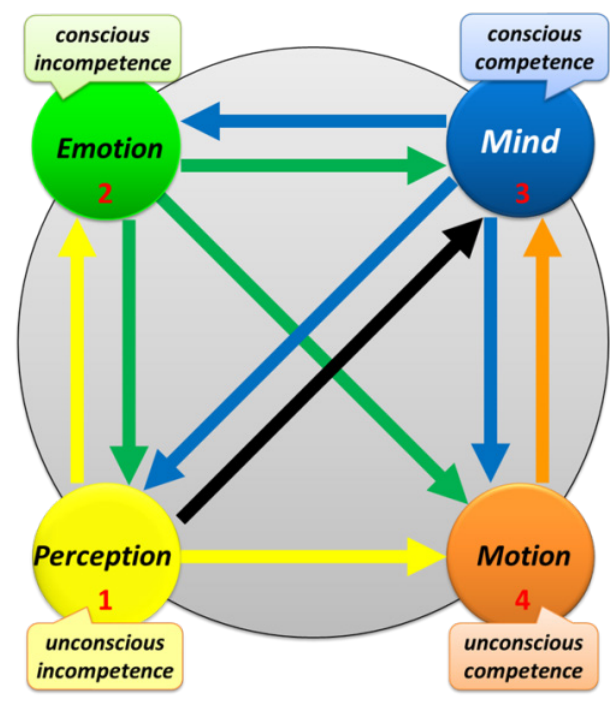

Figure 1. Way competency (skill)

1. A person observes the activities of other people, but in the absence of motivation he does not realize the need for such a skill for himself.

2. Awareness of the need causes emotion and the desire to receive this skill.

3. A person studies information and acquires knowledge, which leads to the ability (conscious competence) to perform the necessary actions.

4. Training and practice lead to the formation of a skill that allows performing actions without conscious control, automatically. Practical applications for real problems lead to better skills and increased skill.

This is the classical way of conscious learning. It is declared in most educational systems and organizations, but, unfortunately, in the absence of motivation for students, a formal approach to the subject of instruction and a minimum of practice, it degenerates into a formal educational path typical for formal educational structures (path 1-3 in Figure 1, shown by the black arrow).

The knowledge obtained in this way is not supported by practice, causes a minimum of interest and does not imply subsequent practical use. Therefore, after a formal check and receipt of marks, they are usually very quickly forgotten, and this all ends.

In Figure 1, we can observe other ways that lead to the desired skill, and correlate them with known or new training approaches. 
So, direct way 1-4 is a way of imitation, copying. Very simple and effective, as it involves specially designed for this brain mechanisms - mirror neurons. Unfortunately, it is used mainly only with young children and primary school students. Although in some areas it can give better and faster results in comparison with the theoretical approach and for adults.

The path of imitation, reinforced by motivation and interest (1$2-4)$, we called modeling. It is well represented in the well-known classical studies (for example, in the concept of social training Bandura [5]).

Path 2-4 is a path of trial and error, possible in the absence of sources of information and a sample for modeling. He is also the path of insight or insight in the implementation of new, previously non-existent activities.

Also on the scheme, you can observe more exotic, but at the same time more efficient ways. For example, as in the approach of Galperin [3] 2-1-4-3-4: motivation - demonstration - independent execution in reality - pronouncing out loud - talking to oneself full automation of the skill.

Of special interest is the path of visual modeling proposed by the authors of this article [6] (1-2-1-4). In this case, the verbal, abstract description of the mode of activity is replaced by a schema, a visual model, which serves as an indicative basis for the activity being mastered see Figure 2.

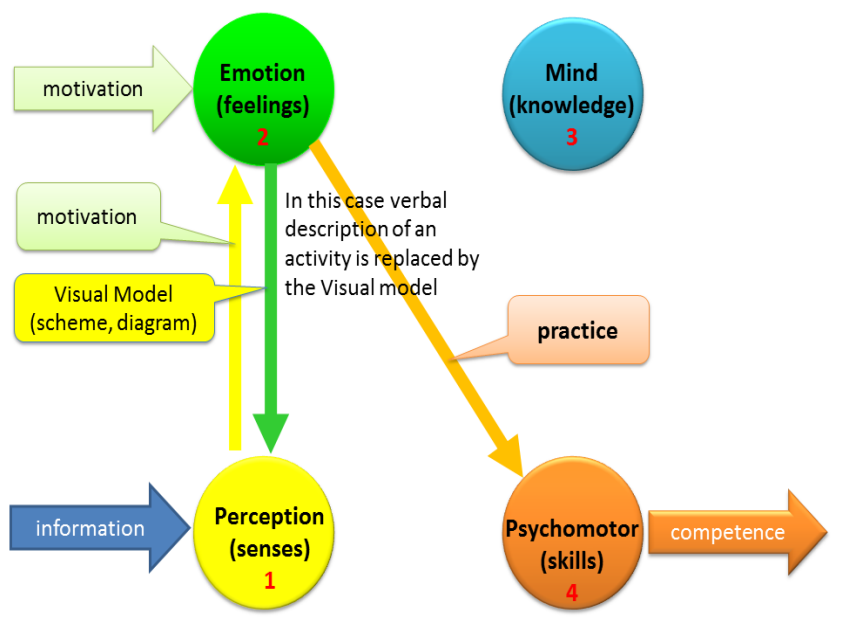

Figure 2. Proposed way of competency.

Such an approach has recently been rapidly gaining popularity in connection with the development of computer systems, visual interfaces, visualization tools, infographics and methods of visual thinking.

\section{Methods for Improving Adult's Foreign Language Skills}

The objective of this project is to elaborate a new inductive methodology of language skills on the basis of the StructuralVisual method (SVM) and the Visual-Auditory Shadowing method (Nakayama \& Mori, 2012) [7]. The Structural-Visual Method is a new inductive language learning methodology, based on mapping of the structure of linguistic knowledge in a graphic form using color to encode the most common patterns [2]. The models thus obtained replace the textual explanations (rules) in the formation of the corresponding skills. The Visual-Auditory
Shadowing method (VAS) is also an inductive language learning methodology which facilitates learning of phonological knowledge (pronunciation) and ideographical knowledge (spelling) [8].

\subsection{Improving listening skills}

Shadowing is the best method to develop a phonological loop to form the skills of understanding by using communication of auditory images with speech movements. according to Tamai (2005) [9], Shadowing is "an act or a task of listening in which the learners track what he/she heard in speech and repeats it as accurately as possible while listening attentively to the in-coming information (p.34)", the shadowing method is effective in improving phonological loop process, and it leads to improvement in listening skills.

VA shadowing method is a combination of auditory shadowing and visual shadowing. Auditory shadowing requires so-called online processing of auditory input, which requires listening and repetition at the same time. Visual shadowing requires learners to read text aloud employing online processing [10] according to Nakayama (2017), VA shadowing method better improves learners' listening skills, compared to shadowing method alone.

By using auditory images allow one to understand different voices and accents, it is played an important role to implement the concept of "Repetition without repetition", where each presentation of the same material is produced by different voices, with different speed, tone, intonation and accent, is of interest.

For more rapid formation of sound filters and pronunciation patterns, it is proposed to use the technologies Textto-Speech, voice recognition, audio file decoding and other achievements of computer technology. The need for multiple repetitions can be used to simultaneously develop both speech skills and linguistic competencies. For this purpose, a combination of the VA shadowing technique, enhanced by the use of computer technologies, and the technique of Structural-Visual modeling.

\subsection{Improving language skills}

In the study of language, the language is the subject of research, and at the same time the research tool, which is already methodologically incorrect. The researcher is produced in the native language of the researcher, and the grammar structure of this language inevitably mediates the way and structure of his thinking. Therefore, language implicitly is also a method of investigation. The result of the research is usually a scientific publication, which is a language product - text. Thus, in the study of thinking, language, language activity and teaching methods, language is also a subject of activity, an instrument of activity, a mode of activity and the result of activity. What cannot but lead to confusion, contradictions and excessive complexity due to logical closure and looping. To eliminate this confusion, it is suggested to make a description of the structure of the language from the sphere of the same language and apply the Visual Metalanguage. Moreover, information about the structure and laws of processes is not coded by words and terms, but by the parameters of abstract visual objects and figures-by the color, shape, size, relative location, boundaries, etc., as well as by special signs and symbols. 


\section{I.H. Tahini et al. / Advances in Science, Technology and Engineering Systems Journal Vol. 3, No. 5, 277-287 (2018)}

Particularly productive was the use of this approach to explain to the student the structure of the language being studied and the principles of constructing sentences. As you know, conscious practice is much more effective than mechanical copying and repetition. This is repeatedly confirmed in the studies and underlies the theory of successive formation of mental actions Galperin [3] and developed on the basis of its methods of practical development of skills in various fields of activity $[3,11]$. But in the field of language teaching, this approach does not work because of the above contradiction - the language must simultaneously be both a subject of educational activity, and an instrument of this activity, and the way of this activity, and the result of this activity. If the student does not know how to express an idea and form a phrase in the language he is studying, he cannot do this because of this ignorance. And if he got the knowledge how to do this, with the help of rules and terms, he still cannot do this because the speech area of the brain, which should implement the act of speaking, is busy with the language information on how to carry out this activity.

The proposed visual approach to the coding of grammatical information allows us to translate the orientation basis of activity, information on how to properly perform this activity, from the language, verbal form to the visual, visual. Releasing this speech zone from the functions of planning and controlling utterances and creating conditions for easy and unhindered performance of speech activity. Language activity itself is meaningless. Language is an instrument for thinking and communicating, and manifests its properties only in such activities. Therefore, the study of language as an end in itself is also unjustified and illogical. It is necessary to teach not language, but activity through language, that is, thinking and communication, which is emphasized in the documents of the Council of Europe [12].

Psychological science did a great deal in the 20th century to study human activity, and to find the patterns of obtaining skills for its implementation (Skinner [13], Bandura [5], Leontiev [14], Galperin [3], etc.). The obtained data made it possible to develop sufficiently detailed theories and, on the basis of them, to create systems for accelerated training of specialists in specific industries (the army, special services, certain spheres of production and technology, large corporations). The closed nature of these areas and the lack of interest in disseminating such experience have led to the fact that these studies are unknown to the overwhelming majority of specialists engaged in the development of similar systems in other industries and countries. This forces them to use outdated, inefficient models and approaches developed for other conditions and tasks and applied in pedagogy because of the conservatism of educational systems.

Galperin [3] in his theory of the step-by-step formation of mental actions pointed to the need for an indicative stage in mastering the skill of mental action, emphasizing the importance of auxiliary tools that facilitate this orientation - the so-called schemes of the Basis of Activity.

A similar approach in Western pedagogy is widely known as Instructional scaffolding. This theory was developed around the same time by (Ninio \& Bruner) [15].

Both these theories are based on Vygotsky's idea of a zone of proximal development [16]. Additional support tools and instructions can be provided through the sensory, motor and verbal channels.

A similar phenomenon was discovered in the experiments of Zhinkin [17] in the middle of the last century, and the low effectiveness of grammatical rules in the mastering of oral speech was repeatedly declared by many linguists and psychologists (Krashen [18], Pinker [19] and etc.).

To resolve this discrepancy, suggest applying SVM. SVM in linguistics is a layout of the structure of linguistic knowledge in graphical form using the color of visual objects to encrypt the most common patterns. The obtained models thus replace the textual explanations (rules) in the corresponding skill formation. For this it is proposed to use another part of the psyche - a nonverbal visual system. The one that is usually located in the right hemisphere of the brain.

The higher efficiency of this method compared to other Visual Aids follows from the features of the functioning of the human visual system, shown in recent studies by Kozlovsky [20]. In them, the conceptual model of Baddeley's work memory [21] was confirmed at the physiological level, in particular the part where the presence of visual working memory is declared, which functions independently of verbal working memory ("visualspatial matrix").

The visual approach to learning foreign language removes the main contradiction of the grammatical method - grammar rules block speaking. If the student does not know how to say the phrase in English, he cannot say anything, because he does not know how to do it. But if you learned the rule how to do it, you still cannot say a phrase. Because that area of the brain, which is responsible for speaking, is occupied with this rule.

SVM show the structure of the sentence in a visual way, freeing the speech zone from the functions of planning and control of speech in the studied language.

The priority direction is the development, research and application of visualization, visual representation of information, visual thinking in different spheres of activity. LingvoMap - a visual representation of the structure of the English sentence and a wide range of tools based on them. The Structural-Visual Method (SVM) is a method of visual structuring of knowledge in the domain by means of color coding of the properties of basic elements. The method allows you to make the complex simple by showing what other people are just telling about.

SVM -it is a set of simple schemes of 3 types, showing:

- Diagrams - the structure of relations between elements of the English language.

- Dynamics - the structure of the Russian language and its relations to the described processes and phenomena.

- Models - the structure of the English proposal and how to build it.

This is the main training material for training on Visual-Body Modeling of the structure of the English language.

Visually - The body method of modeling the structure of the English language radically changes the very approach to the study of English grammar. 
The structure of the division of the grammatical system into its component parts is changed, as is the sign system of the description of this structure.

Verbal rules are replaced by diagrams:

- Abstract scientific names of forms and phenomena are replaced by specific visual parameters of the graphic elements of the schemes - color, shape, location.

- Instead of searching for direct links between grammatical forms of two languages that are extremely complex, ambiguous and not formularized, an intermediate sign system is introduced in the form of abstract graphic images uniquely related to real situations in a certain context.

- Instead of classifying grammatical phenomena in form, another structure is introduced, where the elements are linked by the general logic of development of processes and meaning.

- Instead of analyzing abstract sentences from educational texts, specific physical actions of the teacher and student are performed, which are carried out in reality.

Logical operations to understand structure and connections are carried out not on the verbal plane, but with the help of figurative and subject-active thinking.

We developed the LingvoMap - a visual model of the structure (grammar) of the English language.

This technique [22] replaces:

- Complicated rules - easy and comprehensible schemes.

- Abstract theory - practical and comfortable tools.

- Formal book phrases - usual physical actions.

- Hundreds of pages of verbal description - a complete and harmonious system, located on one sheet.

Without going into the theory, we can create phrases of any complexity.

This will allow you to understand how the English language is organized in just a few hours. And hundreds of hours of saved time you can send to the practice of phonetics, vocabulary and conversation.

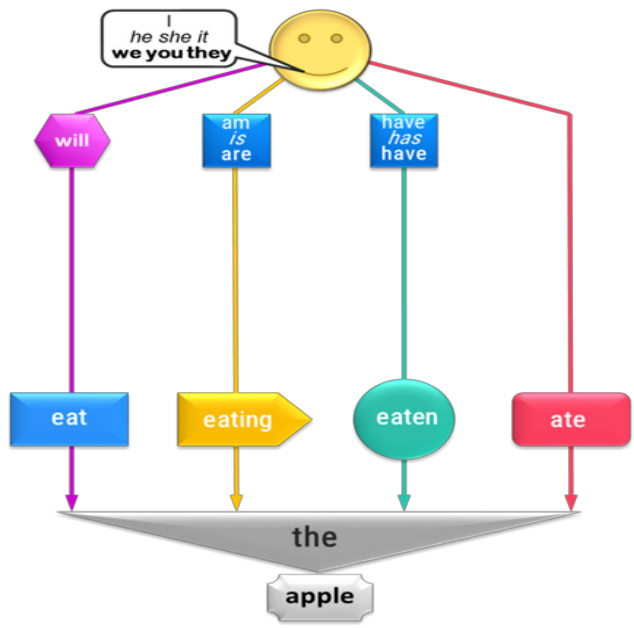

Figure 3. Model of a simple narrative sentence for a verb of action.

Models contain the essential set of temporary structures and development of the kinds of supply required for this level of language capability or as per the educational programs of this training course. For instance, the least difficult model for building a basic account sentence in 4-time forms for an activity verb appears in Figure 3.

Figure 4 shows a more detailed model that allows you to build on it proposals of different forms (narrative, interrogative, negative) and for more times.

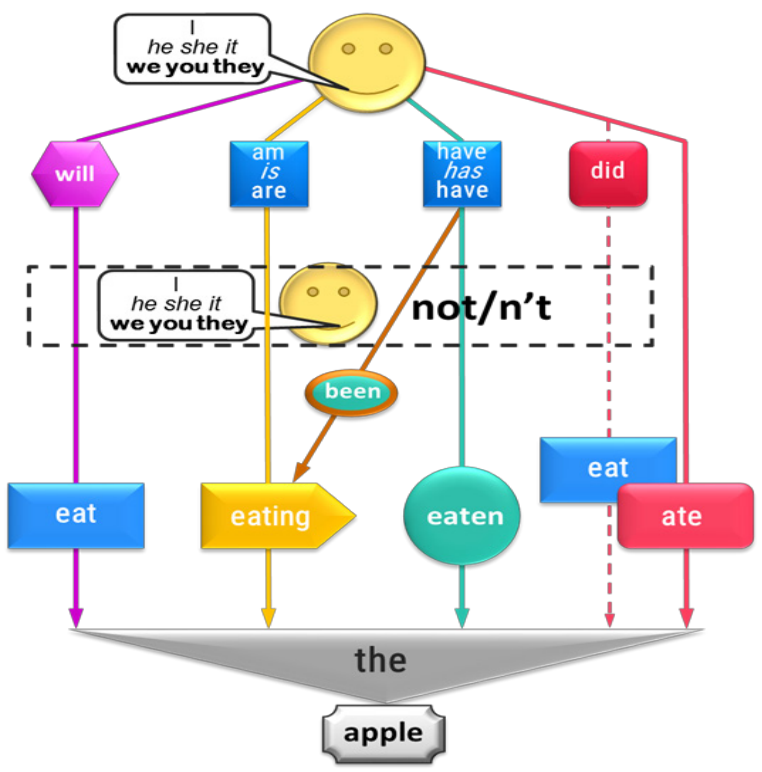

Figure 4. Model for different forms of sentences with action verbs.

In Figure 5 shows the full model of all types of active forms of active voice. It can be applied at higher levels of grammatical competence to systematize knowledge and understand the complete structure of a system of times.

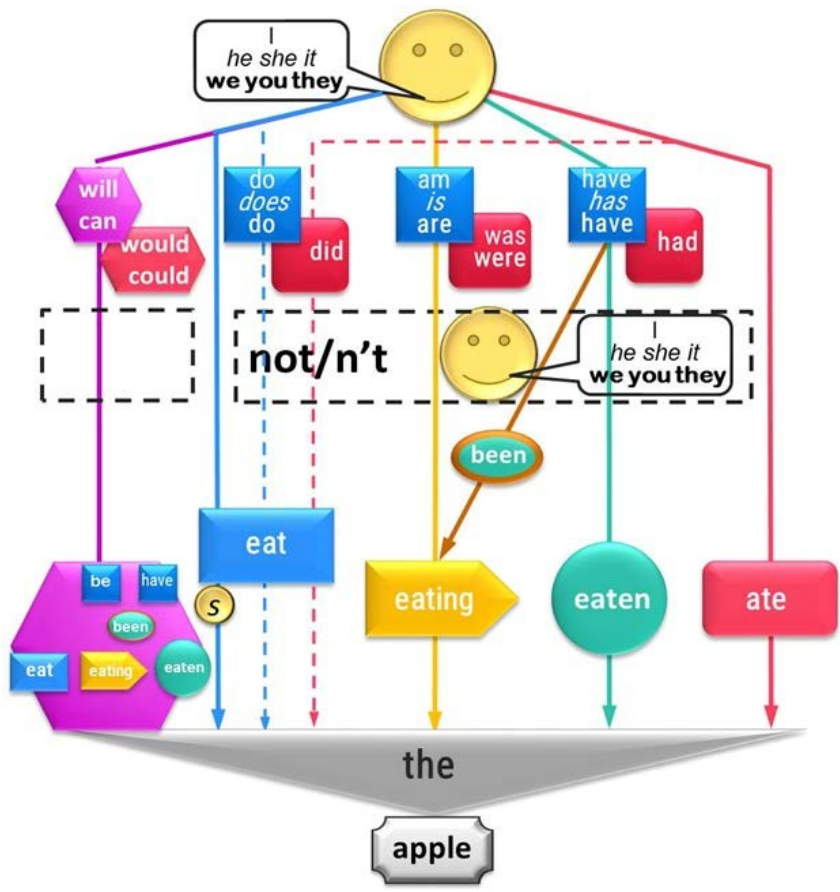

Figure 5. Full model of all active lien times. 


\section{I.H. Tahini et al. / Advances in Science, Technology and Engineering Systems Journal Vol. 3, No. 5, 277-287 (2018)}

Also, models have been created to study individual grammatical topics - passive voice, modal verbs, impersonal verbs, conditional sentences, and many other difficult to understand topics.

\subsection{Training skills}

The research method is to conduct classes with control groups of trainees in various methods of teaching foreign languages. Based on the results of each lesson, a detailed statistical analysis of the results is carried out, dynamic learning curves for each student are displayed, coefficient tables are established and the speed of the formation of listening comprehension skills is determined, speech levels from the initial to the threshold level of spontaneous speaking are determined in accordance with the CEFR [12] scale.

The peculiarity of the proposed approach is the logical interconnection of the entire language system, the economics of the time of mastering the material and the dynamics of the use of language structures. The achievement of results should be achieved by maintaining the level of the student's effort at a sufficiently long interval of time (months, years), which plays a decisive role in foreign language learning, "Figure 6".

The research will enable to achieve the following goals:

1. Identify the mathematical patterns of the formation of basic language skills; test some hypotheses of linguists about the nature of these processes (Krashen [18], Pinker [19], etc.).

2. Integrate models of neurolinguistics and cognitive psychology into pedagogical practice and methodological development.

3. Create effective computer tools for measuring, managing and controlling basic language skills.

4. Create a framework for the effective interaction of representatives of computer technologies and the humanities.

\begin{tabular}{|c|c|c|c|c|c|c|c|c|c|c|c|c|c|}
\hline \multirow{2}{*}{$\begin{array}{l}\text { CEFR } \\
\text { Levels }\end{array}$} & \multirow{2}{*}{$\begin{array}{c}\text { Cambridge } \\
\text { Exams }\end{array}$} & \multicolumn{12}{|c|}{ Months } \\
\hline & & 1 & 2 & 3 & 4 & 5 & 6 & 7 & 8 & 9 & 10 & 11 & 12 \\
\hline$C 2$ & CPE & & & & & & & & & & & & \\
\hline C1 & CAE & & & & & & & & & & & 177 & 191 \\
\hline B2 & FCF & & & & & & & & 126 & 14. & 1 & 164 & \\
\hline & & & & & & 77 & 94 & 1 & 112 & 127 & & & \\
\hline B1 & PET & & & & - & 1 & 78 & 95 & & & & & \\
\hline A2 & KFT & & & & 00 & & & & & & & & \\
\hline & & & & 40 & 41 & & & & & & & & \\
\hline A 1 & & & 24 & 25 & & & & & & & & & \\
\hline & Lessons & 1 & 10 & & & & & & & & & & \\
\hline
\end{tabular}

Figure 6. An approximate comparison of the number of lessons in E-AMS with CEFR levels and the Cambridge Common English exams.

After passing the training, without going into the theory and without using formal rules, you will be able to:

- Correctly formulate your thoughts in English;

- To see the logic of application of different designs, their interrelation and correspondence to different contexts;
- Make phrases of any complexity, in all persons, pledges, times and forms;

- Use as learning materials not abstruse textbooks and tedious texts, but your favorite films, serials, songs, books;

- Freely transform any sentence from these sources into hundreds and thousands of others grammatically correct;

- Independently control the correctness of their statements in conversations, letters, texts, translations and exercises and not depend on teachers, teachers, translators.

Training, like any other theoretical preparation, requires the material to be fixed with practical exercises in the proportion of "1 hour of theory - 10 hours of practice"

Without long training, the knowledge and skills you have gained will not do you any good. Language is a skill and all its aspects should be brought to full automaticity!

The fact that new tools allow you to get a skill easier and faster does not eliminate the need for practice, but only increases its effectiveness.

\subsection{Methodology of the Study}

Learning activities for mastering the language are also infinitely complex and have an unlimited number of parameters and connections. Therefore, to manage this activity it is necessary to apply an abstract scientific model with a minimized number of parameters. In [23] we distinguish the following with minimum set of events.

Set of events (Single event): A single event is one and the same event, the development of which in time is described by the same verb in different forms.

For example:

I will eat an apple. I am eating the apple. I have eaten the apple. I ate the apple.

The minimum set of vocabulary: We confine ourselves to the most minimal set of vocabulary, sufficient for conducting measurements.

In Figure 3 a minimal set of vocabulary is used:

- A complete set of personal pronouns;

- Minimal set of the same verbs (1-8 pieces);

- Minimal set of similar objects (for example, fruits) (2-10 pieces);

- Service words, without which it is impossible to do (articles, auxiliary verbs);

The minimum set of grammatical: To measure the speed of acquiring a skill, let's select the minimum unit of the grammatical skill - this is the ability to compose a phrase according to one template (one form of the sentence for one-time form and one person).

For example, the first template:

This is an apple. This is a pear. This is a peach. 
Second template:

I am eating an apple. I am eating a pear. I am eating a peach.

Changing one parameter of the template, you can measure the speed of acquiring lexical skills (learning words) - as in the examples above or grammatical skills on an established set of types:

-Change by persons (conjugation):

I am eating an apple. He is eating an apple.

She is eating an apple. It is eating an apple.

You are eating an apple. We are eating apples.

You two are eating apples. They are eating apples.

-Change in the stages of development of the event (times), initial dynamics [23] (4 elements):

I'll eat an apple.

I am eating the apple.

I already have eaten the apple.

I ate the apple.

-Change in the form of the object (pragmatics):

He is eating a peach.

He isn't eating a banana.

Is he eating a peach? Yes, he is.

Is he eating a banana? No, he isn't.

Who is eating a peach?

What is he doing?

What is he eating?

As we can see, this grammatical set forms $8 \times 4 \times 7=224$ variants of constructions for describing a single-type event.

\section{Structure of New LMS for IT Development}

In the modern era of information technology development, the information process penetrates into all spheres of human activity, including education. There is an improvement and mass dissemination of modern information technologies (IT).

The relevance of the study of the problem of using IT in the teaching of foreign languages is that information technologies have high communicative capabilities, promote the development of knowledge and skills of speaking and listening skills, actively include them in educational activities and effectively develop the skills of communicative competence. All this is necessary for a successful life in the modern world. It should also be noted the enormous popularity of the Internet and computer technologies among young people.

The purpose of the study is to consider the possibilities of using IT in the teaching of EFL. IT include various software and hardware devices and devices that operate on the basis of computer technology, as well as modern means and information exchange systems that provide collection, storage, storage, production and transmission of information which help to facilitate of production new type of software for the self-teaching the languages.

The use of computer technology contributes to the removal of the psychological barrier of the student on the way to the use of a foreign language as a means of communication. One of the manifestations of this barrier is the so-called fear of error. Trainees note that when using computer technology, they do not feel uncomfortable, making mistakes, and receive fairly clear instructions on how to overcome them.

It should be noted that ITs are not only a means of supplying material, but also a means of control. They provide high quality presentation of the material and use various communication channels (text, touch, graphic, sound, etc.). New technologies allow individualizing and intensifying the learning process. The trainee can choose his educational route and move along it at a convenient pace. A differentiated approach creates the conditions for successful activity of each student, provoking positive emotions and, thus, increasing his educational motivation. Another positive aspect of the use of IT in the learning process is its ability to make the student's assessment more objective (assignments with pre-determined evaluation criteria make it possible to avoid the subjectivity of the assessment).

To control the process of formation of language and work skills of adults, the authors recommend a conceptual solution in the form to create a training system [24]. The generalized structure of the new generation LMS is shown in Figure 7.

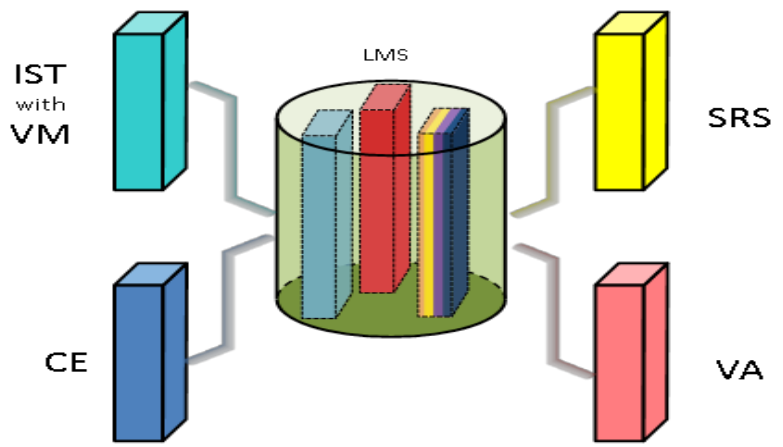

Figure 7. LMS Generalized structure.where: IST with VM - Interactive Speech Trainers with Visual Models, SRS - Speech Recognition System, CE Continuous Evaluation,VA - Virtual Assistant

This new training system [8] will integrate the following points:

1) Methodical principles substantiated in the works of Bandura [5] and Galperin [3].

2) Unification of visual models and interactive visual-auditory tracking, generate a synergistic effect, both in the first stage of mastering a foreign language and in a "barrier to overcome" phase.

3) Use the achievements of the field of information technology as a tool to ensure the implementation of learning objectives with continuous monitoring of the current situation and obtain the results of learning assured in a limited number of steps.

4) Further development of the main components of the LMS is carried out in the following interrelated areas. 
5) It is proposed to use SVM in combination with the modified VA method. Using a new type of LMS provides:

- Step-by-step deceleration and acceleration of the speed of speech in a programmatic way to facilitate the formation of correct pronunciation.

- Application of reference sound templates and speech simulators.

- Repetition without repetition - use for each approach of a material changed by some parameter (voice, tempo, height, lexical or grammatical transformations).

Setting up a subsystem for continuous assessment and realtime learning management will allow us to create logarithmic support for the learning curve and to compensate for the basic requirements of the learning curve to deteriorate to expected loss of efficiency.

The use of modern information technology with the use of effective skills acquisition models allows to reduce the impact of various psychological obstacles and thus accelerate learning and improve its success by conveying a synergistic effect to all phases of language skills [24], especially "barriers to overcome" (Figure 8).

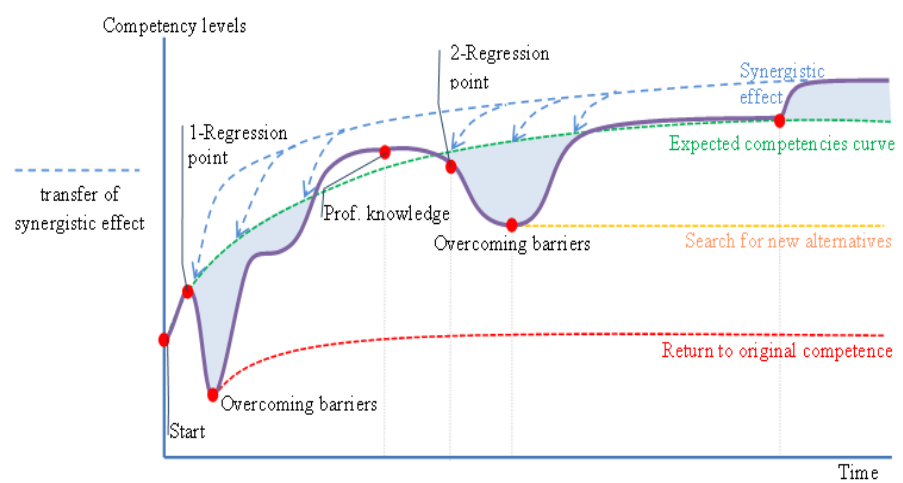

Figure 8 . The learning curve with the transfer of synergistic effect.

Training organized in this way will provide the process of controlling the formation of speech skills to a threshold level, allowing the transition from studying the language to improve the process of use. Measuring and verifying the digital parameters of this process will allow access to the data needed to build an automatic language acquisition control system, which in fact opens a new direction to research the construction of the LMS.

\section{The Proposed Approach}

The result of our analysis is a link between theory and practice, IT and humanities field, science and social processes to create a new generation of Learning Management System (LMS), this system currently under construction, so the requirements of this software are collected; now we are going to a stage of designing and development.

The main contributions of this paper are:

- Working with the real-time voice processing and voice recognition that provide user inputs and system outputs to reach a correct pronunciation.
- We present an API for JavaScript specifically designed to support building such design for "LingvoMap" (Map for construction a sentence (SVM)).

- The effectiveness of this approach by conducting a several prototypes of "LingvoMap" developed using the proposed API requiring well-timed inputs and outputs in real-time.

- This prototype of software runs on both Desktop and Android platforms, which corroborate that cross-platform, web LMS to accelerate learning for learner inputs provided via voice and recognition processing and view the action images.

The software developers formulated several requirements for this system that will be developed in accordance to:

- Availability is the ability of the system to locate and access to training components from a remote access point, and to supply them to other points.

- Adaptability is the ability to adapt the curriculum according to the needs of organizations and individuals.

- Efficiency is the ability to increase productivity, reducing the time and costs of delivering instructions.

- Longevity is the ability to meet new technologies without additional and expensive refinement.

- Interoperability is the ability to use learning materials regardless of the platform on which they are created.

\subsection{Prototype of Platform with Speech Recognition System}

In order to achieve the prototype [25], we consider the following steps:

Database Design: It is a relational data tables contain the information about lessons to extract the information to the system and the result about any training lesson will be stored in database.

The implementation of the LMS Platform: The implementation of the Platform will be using API for C\# and JavaScript, as the HTML5 standard emerged, new opportunities for the development of robust and efficient APIs that support voice processing, and this powerful, widely adopted standard includes interactions with different media, protocols and programming languages [26]. An HTML5 page can process voice and recognition captured directly from devices possibly available on the user's hardware. In addition, WebGL programs consist of control code written in JavaScript and special effects code (shader code) rendering in an HTML, use developments element to draw WebGL graphics for visual programming of the (SVM) flexibility with the introduction of programmable visual effects and these interact with the web page by means of scripts.

Adapt the speech recognition system in the LMS system: We suggest a mechanism to facilitate interaction between the user and the platform through an interface that uses voice recognition. In our platform, the template consists of an interactive image and SVM representation, which reflects the internal structure of the issue of voice recognition. This module will be integrated into the server and also linked to the ASR system. To do this, the following operations are required: 
- Voice-to-text: The process used for adapt the voice recognition system is the ASR. We will focus specifically in API Google Speech to Text (STT) Service because it is a cloud computing system and does not compromise the performance of the local computer.

- Text-to-Speech: To convert Text to Speech (TTS), we propose to use the cloud services of Google. Using Google Translator, however, is a less complex process compared with ASR.

\subsection{System Architecture}

In "Figure 9" we see the system architecture and explained as follow:

Information Request and Display Module (IRDM): In this module the images that represent the action of sentence are displayed as action image and SVM, and this module allows the user to control by the options of program through the keyboard and computer screen, this information is sent to a Webserver. Once information is processed, the requested are shown to the user as data lesson.

Knowledge Data Formation Module (KDFM): The module consists of a database schema that contains all the relational tables, and is used to describe and represent area of knowledge such as data lessons. Database contains the stored procedures to provide a way to create the content of lesson under user requests depend on the selected options. Web server contains the API for the client part to transfer the received data from database server into a graphical interface for client, the connection from web server to database using data access layers these layers contain connection manger and business layers which contain a set of objects (Classes) that return the data as dataset to be used by web services and JavaScript and WebGel with the use the services of Google for speech and recognition.

Speech Recognition Module (SRM): This module allows to the learner to interact in our Platform by using voice. For instance, the system returns the information to the SRM in order to be converted to speech using TTS (Text-to-Speech). The user speaks for information in the microphone and such consult is converted to text in the ASR system. In web server the java script functions check from this input data if it is correct to the displayed text at IRDM. Finally, the feedback of correct speaking will be saved in database for evaluation.

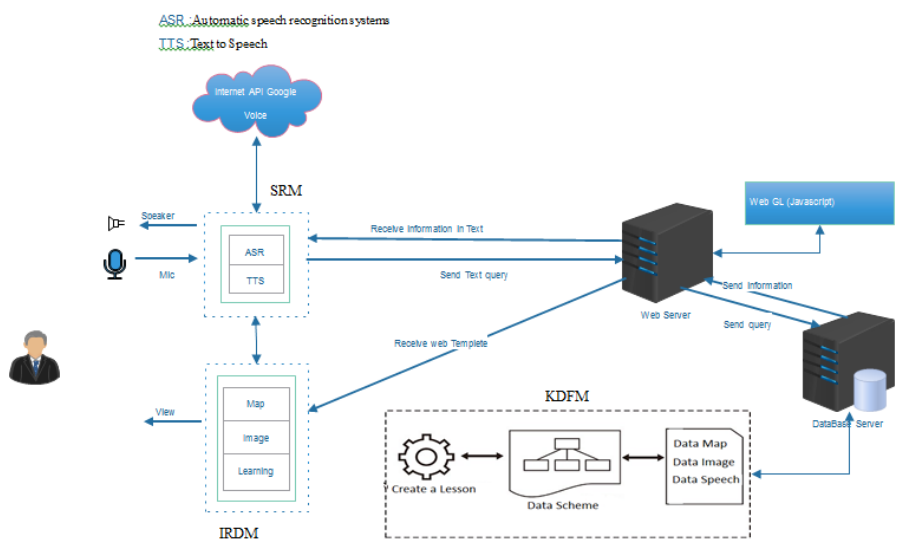

Figure 9. System Architecture

\subsection{Working of Software}

An educational object of LMS is any educational material that can be displayed in a web browser (for example, texts, pictures, voice and Map, web pages), as well as any combination thereof, intended for educational purposes and collected together in a special way. In addition, the browser must be implemented and enabled for the JavaScript language. Thus, this software standard describes database for training materials contains:

- Educational materials in the form of data in relational tables.

- Arbitrary dynamic content: JavaScript code and other objects that can be displayed inside the browser. Dynamic content can inform the LMS of the student's progress.

- All study materials are structured (i.e. break into lessons or level of Lessons).

- The description of the material flow sequence is indicated. For example, a specific text should be provided to the learner only after he has read other texts or passes the test.

The main flow of events: begins when the user intends to work with training courses containing SVM-objects and voice recognition. The system should offer one of the following options:

1. Load data lesson from a database.

2. Load the image and "LingvoMap".

3. The simulator should speak, and the learner should listen and vice versa, the learner should speak, and the simulator should understand it and give feedback.

4. The result of training will be saved in database to display the level of training at learning curve.

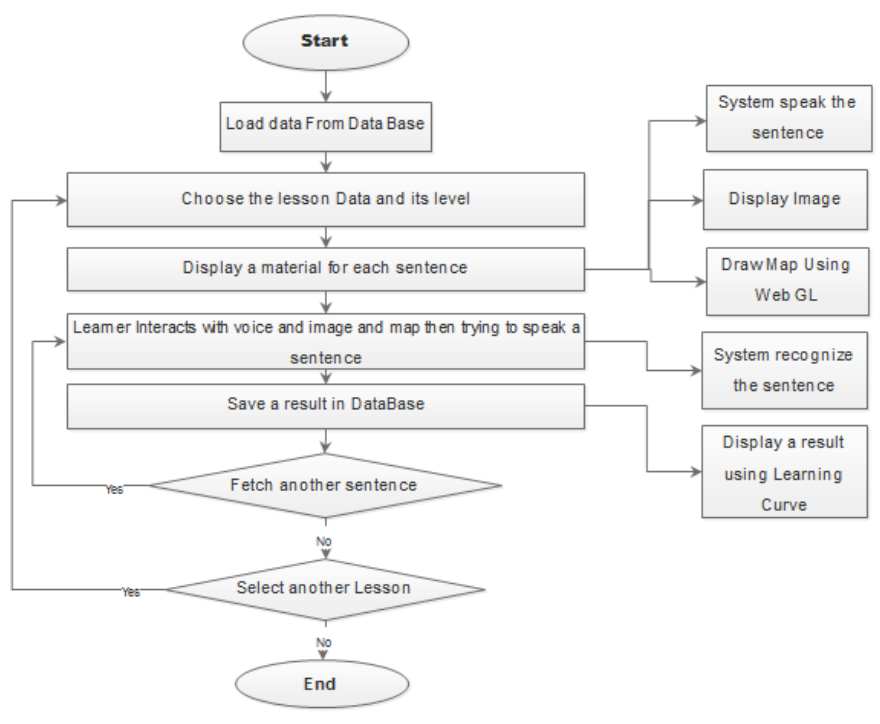

Figure 10. Flow Chart of a lesson

In the IST (Interactive Speech Trainers), the data will be loaded from database into the interface, we set the interface to select the lesson then choose the level of each lesson, so the level will be determine the change of model of structural visual model, each level of lesson contain the structure of (SVM) start from simple then going to full model of (SVM) due to the structure of lesson and its words, so the data of lesson will be set from back-end content management system (CMS), in "Figure 10" we see the start 
workflow of the process of the lesson, the material of a lesson's level contain set of sentences with its components that will be generated automatically on running the system (Images ,Sound, SVM), the user will interact with these material by hearing and speaking a sentence and save the feedback in Database to display these results in learning Curve.

The User Interface of the webpage is shown in Figure 11, which let the user login to the system. When the login is a success then the user can access to material that contains a list of lessons for the user to select the target lesson.

Visually, the description of LMS can be represented as a set of lessons, each describing a certain part of learning process "Figure 6".

\section{lingvomap Home Material Learning Curve Language - CMS- About Contact}

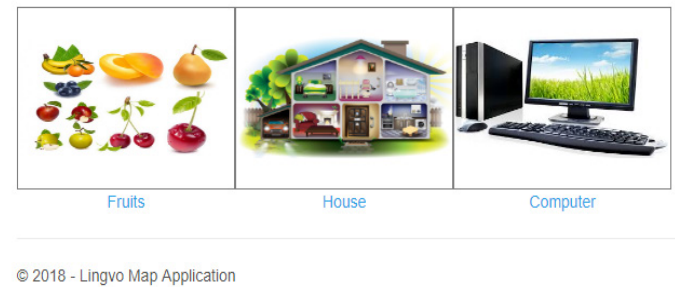

Figure 11. Set of Lessons.

From a list of lesson that displayed on screen, select any lesson to load the content and to display the SVM and images of lesson, "Figure 12".

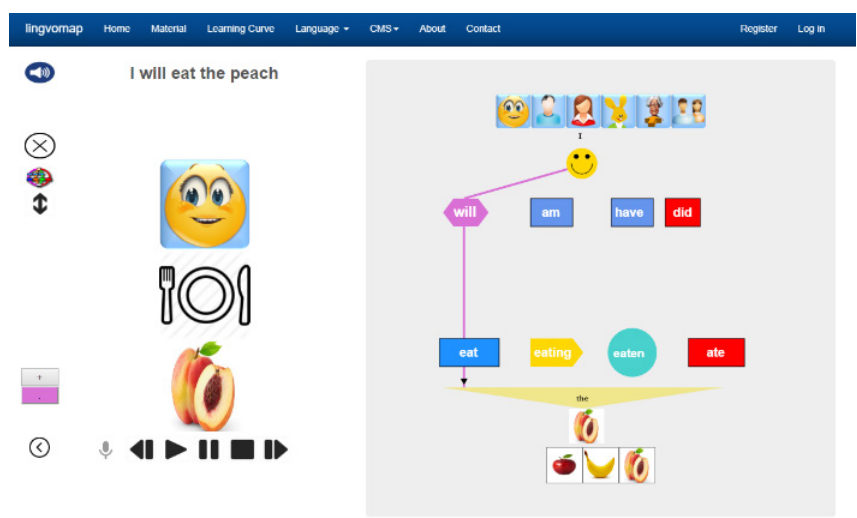

Figure 12. Interface of IST

In addition to providing training courses, the Continuous Evaluation subsystem of the lessons can inform us about the results of the training to do more evaluation by user to reach the satisfactory level "Figure 8". For example, when completing a task, the student received a certain number of points and spent a certain amount of time performing; Learning curves are adequate for evaluating performance improvement due the positive effect of learning.

\subsection{Content Management system}

Managing Web content is becoming a top priority for improving business performance. Careful planning and elaboration of this process is required, and timely and prompt updating of the information content of the resource plays one of the main roles in the success of the project.

The educational content of Current software is understood as the set of educational lessons collected in sentences, SVM, action images, learning result. These content units are designed as a template in such a way they can be used repeatedly in a different lesson. For example, once the template of lesson content is created, it can then be used in any new lesson with a change of words, when a need arises.

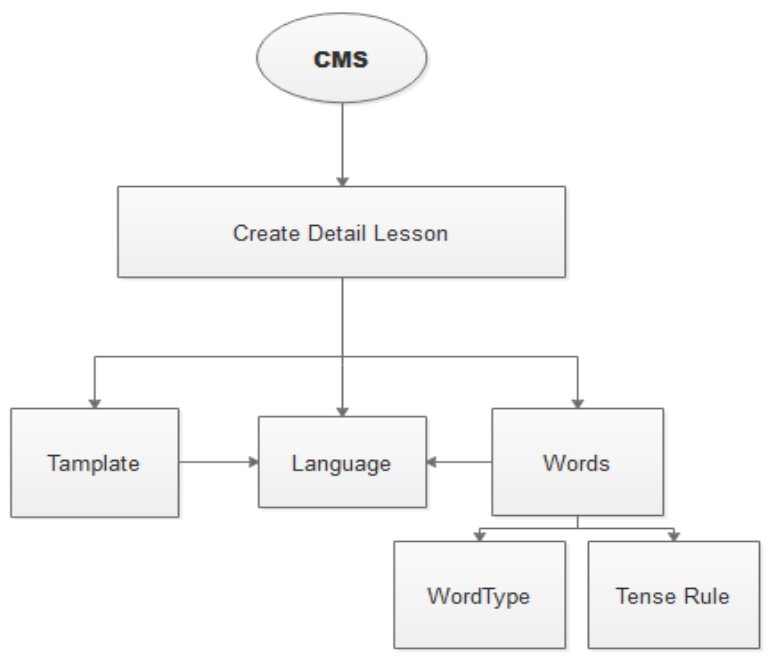

Figure 13. Flow Chart of CMS

To Control the content and images of lesson, we need to fill the data for each lesson, in "Figure 13" we have the flow charts of lesson that composed of Template, language and words the words related to word types (Verb, object, ...) and Tense Rule (Past simple, Future,...).

To create the lesson, there are main components that will be considered in order to complete the structure of the lesson, where Template, Language and words form the complete data of lesson.

Template: it is a set of structures and form type (positive sentence, negative sentence, question, ...) of a sentence, structure is a set of combination of word type (Subject, Verb, Object, Auxiliary, ...) by aggregation of these word type by add symbol '+' between them for example (Subject+Verb+Article+Object), by generate the function of a given template of a lesson we get a set of lesson data from this structure by replace subject by $(\mathrm{I}, \mathrm{He}, \mathrm{She}, \ldots)$ and Verb by (eat )and Article by (the) and Object by (Apple) replace ' + ' by ' ' the result is a sentence (I eat the apple), for instance the set of the structure for English language for a given lesson at a given level as (Subject+Auxiliary+Verb+Article+Object,

Subject+Verb+Article+Object, Subject+Auxiliary+not+Verb+Article+Object, Auxiliary + Subject + Verb + Article + Object + ?, ....).

\section{Conclusion}

In this paper, we have discussed the different techniques and new methods of learning to be used in current technology framework for acquisition a language and also reviewed the results obtained from previous papers on this subject. 


\section{I.H. Tahini et al. / Advances in Science, Technology and Engineering Systems Journal Vol. 3, No. 5, 277-287 (2018)}

The application of this approach explaining linguistic phenomena and teaching foreign languages, proposed in this work, allows us to translate the planning and control of speech activity into the right hemisphere and thus greatly simplify and simplify the process of teaching languages.

A prototype was created. To date, we get an encouraging result about the experiments 300 students during the training related with the development of this LMS system.

Exploratory confirmation of preparing materials, test systems and proposed educational programs components of (SVM) on a restricted gathering of pupils demonstrated outcomes like those acquired through the quick advancement of other training methods for the Galperin theory [3]. There was a decrease in preparing time to perform particular work in (3-30 times) and increment in preparing accomplishment by $10-25 \%$ to $80-95 \%$. These are primer outcomes that require extra check and independent testing.

Based on this approach, we are developing a new generation of training and computer programs and we are working to carry out intensive testing and collection of statistical data. Visual models and pedagogical theories, which have received a new incarnation in them, open other horizons and scale prospects for improving educational technologies.

\section{References}

[1] I. H. Tahini and A. K. Dadykin, "A study of new techniques for learning management system to accelerate language acquisition using structural visual models," 2018 Sixth International Conference on Digital Information, Networking, and Wireless Communications (DINWC), Beirut, 2018, pp. 9297.doi: 10.1109/DINWC.2018.8357002.

[2] A.K. Dadykin, V.A. Dibrova and I.H. Tahini, "The Visual Approach in Educational Projects," 4th International Conference on Education and Psychological Science (ICEPS 2017), Barcelona, Spain, February 12-14, 2017 / International Journal of Social Science and Humanity (IJSSH, ISSN: 2010-3646, DOI: 10.18178/IJSSH).

[3] P.Y. Galperin , "Psychology of thinking and teaching about the gradual formation of mental actions", Research in the thinking of Soviet psychology. Moscow, 1966.

[4] A.H. Maslow, (1987). Motivation and Personality. (3rd ed.). New York, NY: Harper \& Row. pp. 117-118.

[5] A. Bandura \& R.H. Walters, (1963). Social learning and personality development. New York: Holt, Rinehart, \& Winston.

[6] A.K. Dadykin, VA Dibrova, Generalized visual model of the structure of the educational process // Modern trends in secondary adult education: Materials of III International. scientific method. Conf., Minsk, October 21. . 2016 .: 2 hours - Minsk RIVSH, 2016 - Part 1. - P. 62-67.

[7] T. Nakayama, T. Mori, Efficacy of Visual-Auditory Shadowing, Tokyo: JStage, 2012, v 42, 55-68 p. ISSN I0917-3536.

[8] I.H. Tahini, T. Nakayama, V.A. Dibrova, and A.K. Dadykin, "Cognitive Psychology Models and Approaches to Develop Language Skills," 5th International Conference on Education and Psychological Sciences (ICEPS 2018), Seoul, South Korea, January 27-29, 2018, International Journal of Information and Education Technology (IJIET, ISSN: 2010-3689, DOI: 10.18178/IJIET)

[9] K. Tamai, "Risuningu shidoho to shiteno shadoingu no koka ni kansuru kenkyu [Research on the effect of shadowing as a listening instruction method]," Tokyo: Kazama Shobo, 2005.

[10] T. Nakayama, "Efficacy of Visual-Auditory Shadowing Method in SLA Based on Language Processing Models in Cognitive Psychology," Tokyo: Kaitakusha, p.110, 2017.

[11] B. Badmaev, Psychology and methodology of accelerated learning. M.: Humanité. Ed. Center VLADOS, 1998 - 272 p. ISBN 5-691-00102-7.

[12] Council of Europe (2011). Common European Framework of Reference for Languages: Learning, Teaching, Assessment. Council of Europe.propositions of Principia Mathematica and related systems I]. Monatshefte für Mathematik und Physik. 38: 173-198.

[13] B.F. Skinner, The Technology of Teaching, 1968. New York: AppletonCentury-Crofts Library of Congress Card Number 68-12340 E 81290 ISBN 0-13-902163-9.
[14] A.N. Leontiev, “Activities. Consciousness. Personality”. Moscow, 1975.

[15] A. Ninio and J. Bruner, "The achievement and antecedents of labeling," Journal of Child Language, No. 5, pp. 1-15, 1978.

[16] L. Vygotsky, "Thought and language," Cambridge, MA: MIT Press, 1934/1986.

[17] N. Zhinkin "About code transitions in internal speech," Questions of linguistics, No. 6, pp. 26-38, 1964.

[18] S.D. Krashen, "Principles and Practice in Second Language Acquisition," University of Southern California, p.202.

[19] S. Pinker, "The Language Instinct: How the Mind Creates Language," William Morrow and Company, p.483, 1994.

[20] S.A. Kozlovsky, "Psychophysiological mechanisms of preservation of visual images in working memory," Available: http: //www.dissercat.com/content/psikhofiziologicheskie-mekhanizmy-so khraneniya-zritelnykh-obrazov-v-rabochei-pamyati\#ixzz4zGVJphTy.

[21] A.D. Baddeley, "The episodic buffer: A new component of working memory? ," Trends in Cognitive Sciences, No. 4, pp. 417-423, 2000.

[22] I.H. Tahini, "New Structure of Learning Management System for Formation of Language Skills by Using Visual Approach", V International Scientific and Technical Internet Conference, November 18-19, 2017 Section Information Technologies in Production and Scientific Research, BNTU,2017.

[23] I.H. Tahini, A.K. Dadykin and V.A. Dibrova. "The Model of Change as the Basis of the Knowledge Structure in the Next Generation E-LMS", 10th annual International Conference of Education, Research and Innovation, 2017, Seville, Spain (ISBN: 978-84-697-6957-7 / ISSN: 2340-1095, doi: 10.21125/ 10.21125/iceri.2017.1325). - Pages: 5022-5032.

[24] I.H. Tahini, A.K. Dadykin, V.A. Dibrova, "Control System of Foreign Language Training Based on Structural-Visual Techniques," Proceedings 4th International Conference on Computer Science Computer Engineering and Education Technologies (CSCEET2017), Beirut/Lebanon: pp.149-154, 2017.

[25] I. Tahini, A. Shaparenko, A. Golikova, A. Dadykin. Management System for Forming Language Skills of Adults - New Generation LMS / EDULEARN 2018 Proceedings 10th annual International Conference on Education and New Learning Technologies, pp. 5061-5071, ISBN: 978-84-09-02709-5, July 2018, Palma de Mallorca, Spain, ISSN: 2340-1117.

[26] S. Fulton, and J. Fulton, "HTML5 Canvas," O’Reilly Media, Incorpo- rated, 2013. 